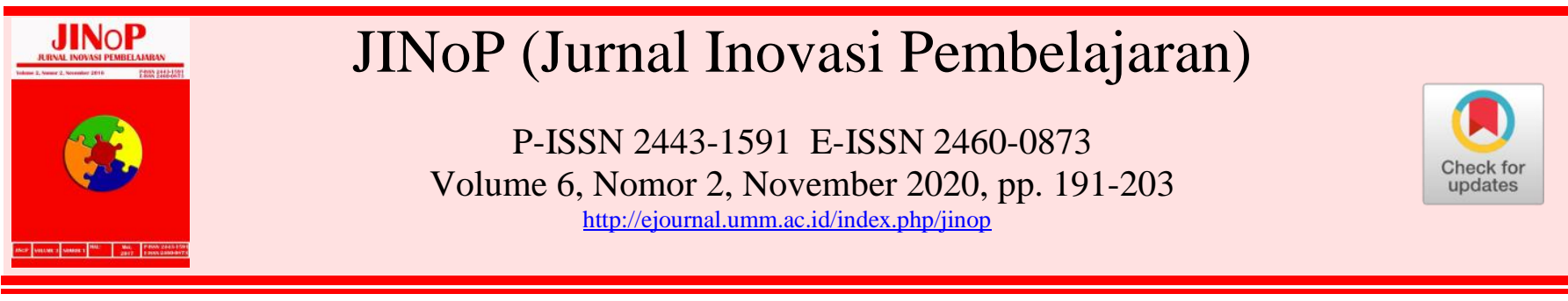

\title{
Pengaruh model pembelajaran RADEC terhadap keterampilan berpikir tingkat tinggi siswa sekolah dasar
}

\author{
Yoga Adi Pratama ${ }^{1)^{*}}$, Wahyu Sopandi ${ }^{2)}$, Yayuk Hidayah ${ }^{3)}$, Meiwatizal Trihastuti ${ }^{4)}$ \\ ${ }^{1}$ Program Studi Magister Pendidikan Dasar, Sekolah Pascasarjana, Universitas Pendidikan \\ Indonesia J1. Dr. Setiabudi No. 229, Kota Bandung, Indonesia \\ ${ }^{2}$ Program Studi Magister Pendidikan Dasar, Sekolah Pascasarjana, Universitas Pendidikan \\ Indonesia J1. Dr. Setiabudi No. 229, Kota Bandung, Indonesia \\ ${ }^{3}$ Program Studi Pendidikan Sekolah Dasar, Fakultas Keguruan dan Ilmu Pendidikan, Universitas \\ Ahmad Dahlan, J1. Kapas No.9, Semaki, Kec. Umbulharjo, Yogyakarta, Indonesia \\ ${ }^{4}$ Program Studi Pendidikan Pancasila dan Kewarganegaraan, STKIP Pasundan, Jl. Permana \\ No.32B, Citeureup, Kec. Cimahi Utara, Kota Cimahi, Jawa Barat, Indonesia
}

yoga.adipratama@upi.edu**,wahyusopandi@upi.edu, yayuk.hidayah@pgsd.uad.ac.id, meiwatizaltrihastuti@gmail.com

*Penulis Koresponden

\section{ABSTRAK}

Keterampilan berpikir tingkat tinggi bagi siswa sekolah dasar sangat penting untuk menghadapi abad 21. Salah satu model pembelajaran yang dapat dikembangkan adalah RADEC (ReadAnswer-Discuss-Explain and Create). Tujuan penelitian ini adalah untuk mengetahui pengaruh model pembelajaran RADEC terhadap keterampilan berpikir tingkat tinggi siswa kelas V sekolah dasar pada tema ekosistem. Metode penelitian yang digunakan adalah kuasi eksperimen dengan the matching pretest-posttest design. Sampel ditentukan secara purposive, dengan siswa SDN 5 Pagarsih sebagai kelas eksperimen dan SDN 1 Pagarsih sebagai kelas kontrol. Instrumen yang dikembangkan mengacu taksonomi Bloom Revisi. Hasil penelitian menunjukkan model pembelajaran RADEC memiliki pengaruh positif terhadap berpikir tingkat tinggi siswa dibandingkan dengan model pembelajaran inkuiri. Hal tersebut diperhatikan dari skor rata-rata pretest di kelas RADEC 40,44 dan inquiri 38.14. Sementara skor rata-rata posttest kelas RADEC 70.08 dan inquiri 56.5. Data tersebut menunjukkan bahwa peningkatan pada kelas eksperimen mencapai 29.64, kelas kontrol 18.36. Sintaks pembelajaran RADEC sesuai dengan konteks keIndonesiaan, khususnya pada tahap Read dan Answer yang membuat siswa lebih siap untuk belajar. Selanjutnya Discuss, Explain dan Create yang lebih efektif dan memudahkan proses pembelajaran. Simpulan penelitian ini adalah model pembelajaran RADEC lebih berpengaruh positif dibandingkan model pembelajaran inkuiri terhadap ketrampilan berfikir tingkat tinggi siswa.

Kata kunci: Keterampilan Berfikir Tingkat Tinggi; RADEC; Sekolah Dasar.

\section{ABSTRACT}

Higher order thinking skills for elementary school students are important to face the XXI century resulting on RADEC (Read-Answer-Discuss-Explain and Create), one of the learning models that can be developed. The purpose of this research was to determine the effect of the RADEC learning model on higher order thinking skills (HOTS) of fifth grade elementary school students on the ecosystems theme. The research employed quasi-experimental model with the matching pretestposttest design. The sample was determined purposively for both the experimental class and the control class. Furthermore, the instrument developed refers to Revised Bloom's taxonomy. The results showed that the RADEC learning model had a positive effect on students' higher order thinking compared to conventional learning models. This can be seen from the average pretest score in the RADEC class 40.44 and 38.14 in the conventional class, while the average posttest score in the RADEC class is scored 70.08 and 56.5 in the conventional class. The data indicated that the increase in the experimental class reached 29.64, while the control class scored 18.36. The syntax used in RADEC learning model is in accordance with the Indonesian context, 
especially in the Read and Answer stages which make students ready to learn. Then, the Discuss, Explain and Create stages are more effective and ease the learning process. The conclusion of this research was that the RADEC learning model has a more positive effect than the conventional learning model. The RADEC learning model improved the thinking skills of the $5^{\text {th }}$ grade students on the ecosystem theme.

Keywords: Higher-order Thinking Skills; RADEC; Elementary School.

diunggah: 2020-06-23, direvisi: 2020-10-17, diterima: 2020-11-20, dipublikasi: 2020-11-20

Copyright (c) 2020 Pratama et al

This is an open access article under the CC-BY license

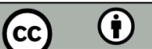

Cara sitasi: Pratama, Y., Sopandi, W., Hidayah, Y., \& Trihatusti, M. (2020). Pengaruh model pembelajaran RADEC terhadap keterampilan berpikir tingkat tinggi siswa sekolah dasar. JINoP (Jurnal Inovasi Pembelajaran), 6(2). 191-203. https://doi.org/10.22219/jinop.v6i2.12653

\section{PENDAHULUAN}

Abad 21 dikenal sebagai abad digital yang ditandai oleh perkembangan teknologi informasi dan komunikasi yang sangat pesat. Perkembangan teknologi informasi tersebut memberikan perubahan pada seluruh aspek konstelasi kehidupan. Implikasinya setiap bangsa termasuk Indonesia harus menyesuaikan dengan tuntutan zaman tersebut. Menurut Binkley (2012), untuk mampu hidup di abad 21, diperlukan sepuluh keterampilan yang harus dimiliki siswa, keterampilan tersebut antara lain keterampilan berpikir kreatif, berpikir kritis, berpikir metakognisi, komunikasi, kolaborasi, literasi informasi, literasi TIK (Teknologi Informasi Komunikasi), berkewarganegaraan, bekerja dan berkarir, serta keterampilan responsibilatas individu dan sosial. Lebih lanjut Trilling, B., Fadel (2009) menggagas konsep pelangi keterampilan dan pengetahuan yang harus dimiliki di abad 21. Keterampilan tersebut meliputi ketarampilan belajar dan berinovasi yang di dalamnya terdapat kemampuan berpikir kreatif dan kemampuan memecahkan masalah, kemampuan komunikasi dan kolaborasi, dan kemampuan untuk berkreativitas dan berinovasi. Keterampilan-keterampilan tersebut jika dicermati lebih lanjut erat kaitannya dengan Higher Order Thinking Skills (HOTS).

Berdasarkan dengan pernyataan di atas, salah satu kemampuan yang dapat mengakomodasi siswa untuk dapat bereksistensi di abad 21 adalah HOTS. HOTS merupakan kemampuan penting, yang mana siswa belajar bukan hanya mengingat dan memahami, namun jauh lebih dalam yakni menganalisis, mengevaluasi, dan menciptakan. HOTS adalah kemampuan rumit yang di dalamnya terdapat kemampuan logika dan penalaran, analisis, evaluasi, kreasi, pemecahan masalah, dan pengambilan keputusan (Brookhart, 2010). Hal tersebut sejalan dengan pendapat Nugroho (2018) yang menyatakan HOTS sebagai kemampuan untuk menerapkan keterampilan, pengetahuan, dan nilai dalam membuat penalaran dan refleksi dalam memecahkan suatu masalah, mengambil keputusan, dan mampu menciptakan sesuatu yang memiliki sifat inovatif.

HOTS ini sangatlah penting jika kaitkan dengan abad 21, maka membelajarkan HOTS sudah menjadi suatu keharusan. Sehingga HOTS merupakan keterampilan penting yang harus diterapkan dalam sistem pendidikan negara, karena HOTS mempromosikan pembelajaran berkelanjutan dan menyumbangkan berbagai manfaat bagi negara di masa depan (Abdullah AH, 2017). Salah satu dampak positif HOTS adalah memaksimalkan kinerja dan mengurangi kelemahan, dengan kata lain peserta didik yang dilatih berpikir akan berpengaruh kepada kemampuan, 
kecepatan, dan efisiensi dalam mengambil keputusan (Yee, Othman, Yunos, Tee, \& Mohammad, 2011).

Namun demikian, fakta di lapangan menunjukkan bahwa kemampuan HOTS siswa masih tergolong rendah. Siswa masih belajar pada tataran mengingat, memahami, dan menerapkan, dan belum terbiasa dilatih pada kemampuan menganalisis, mengevaluasi dan mencipta. Hal ini terlihat dari hasil observasi peneliti yang menunjukkan bahwa siswa cenderung belajar pada tataran LOTS (Low Order Thinking Skills). Hasil studi Saido, et al (2015) menunjukkan bahwa guru lebih banyak membelajarkan siswa untuk menghafal, sementara pembelajaran inovatif seperti pembelajaran proyek, berbasis masalah, kolaboratif dan bersifat inkuiri masih kurang dilaksanakan oleh guru. Hal tersebut tercermin dari hasil studi PISA (Programme for International Student Assesment) yakni peringkat ke 64 dari 65 negara pada tahun 2012 (OECD, 2013) dan peringkat 64 dari 72 negara pada tahun 2015 (OECD, 2017). Peringkat tersebut menunjukkan bahwa siswa Indonesia masih ada pada tataran low ability.

Sudah banyak penelitian mengenai HOTS, di antaranya seperti penelitian Fitri, Dasna, \& Suarjo (2018) yang menyimpulkan bahwa penerapan Model Project Based Learning (PjBL) dapat meningkatkan HOTS. Fatchiyah (2016) dalam penelitiannya juga menyimpulkan bahwa model problem based learning (PBL) memiliki pengaruh positif dan signifikan terhadap HOTS. Terakhir, penelitian Nurhayatii \& Anggraeni (2017) menyimpulkan HOTS mahasiswa dalam pembelajaran fisika meningkat melalui model problem based learning (PBL). Acar \& Aybars (2018) yang menyatakan bahwa pembelajaran berbasis inkuiri dapat mengembangkan keterampilan HOTS.

Namun demikian, model-model pembelajaran inovatif tersebut tidak dapat terlaksana di lapangan. Hasil penelitian Sopandi, Pratama, \& Handayani (2018) menyebutkan bahwa hanya $10 \%$ guru pendidikan dasar dan menengah se-Jawa Barat yang bisa menuliskan sintaks dari model pembelajaran inovatif yang paling sering digunakan. Itu artinya terdapat miskonsepsi guru terhadap model pembelajaran inovatif, sehingga guru hanya merasa melaksanakan pembelajaran inovatif, padahal nyatanya tidak. Selain sintaksnya yang sulit dihafal (Sopandi et al., 2018), model pembelajaran inovatif juga memerlukan waktu yang cukup lama dalam satu kali pembelajaran. Sehingga guru cenderung lebih banyak menggunakan pembelajaran dengan metode ceramah yang dianggap praktis dan cepat, dampaknya adalah ativitas di kelas didominasi oleh penugasan dan hafalan yang memperlihatkan bahwa rendahnya keterlibatan kemampuan berpikir siswa di dalam pembelajaran (Tembang \& Suharjo, 2017).

Berdasarkan pernyataan di atas, maka diperlukan solusi alternatif, salah satunya adalah dengan menghadirkan model pembelajaran yang mudah dihafal sintaknya dan sesuai dengan karakteristik Indonesia. Model pembelajaran tersebut adalah model pembelajaran RADEC (Read-Answer-Discuss-Explain and Create) yang pertama kali diperkenalkan oleh (Sopandi, 2017). Model pembelajaran RADEC merupakan model pembelajaran yang yang menggunakan tahapannya sebagai nama model itu sendiri, yakni Read atau membaca, Answer atau menjawab, Discuss atau berdiskusi, Explain atau menjelasakan dan Create atau mecipta. Model 
pembelajaran RADEC menjadi jawaban atas miskonsepsi guru terhadap model pembelajaran inovatif, selain sintaksnya mudah dihafal (Sopandi et al., 2018), model ini pun tidak memakan waktu yang panjang dalam pelaksanannya. Model pembelajaran RADEC pun telah terbukti dapat memperbaiki kualitas hasil belajar, seperti pemahaman konsep (Lukmanudin, 2018), maupun learning skills yaitu kemampuan berpikir kreatif (Jumanto, Kuncoro, Handayani, \& Suryana, 2018)

Berdasarkan pemaparan di atas, maka peneliti mengambil judul penelitian "Pengaruh Model Pembelajaran RADEC Terhadap HOTS Siswa Sekolah Dasar". Model pembelajaran RADEC akan dilaksanakan pada kelas eksperimen dan pada kelas kontrol peneliti memilih model pembelajaran inkuiri.

\section{METODE}

Penelitian ini menggunakan metode penelitian eksperimen. Secara khusus penelitian ini menggunakan desain kuasi eksperimen. Desain ini melibatkan dua kelompok sampel, satu kelompok sebagai kelompok pembanding atau kontrol dan satu kelompok sebagai kelompok eksperimen. Dalam penelitian ini kelompok eksperimen menggunakan model RADEC, sedangkan kelompok kontrol menggunakan model pembelajaran inkuiri. Desain kuasi eksperimen menggunakan (the matching) pretest-posttest design.

Adapun populasi dalam penelitian ini adalah seluruh siswa kelas V SD tahun ajaran 2018/2019 yang ada di Kecamatan Pagarsih. Pemilihan sampel dilakukan menggunkan teknik sampling purposive. Berdasarkan hasil pertimbangan kurikulum, wawancara dengan guru, dan kondisi sekolah maka peneliti memilih SDN Pagarsih 1 dan SDN Pagarsih 5 sebagai sampel yang diambil dari populasi yang sebelumnya telah ditentukan. Pemilihan SDN Pagarsih 1 dan SDN Pagarsih 5 sebagai sampel penelitian oleh peneliti karena berdasarkan wawancara dengan guru memiliki kemampuan akademik yang hampir sama, hal ini sesuai dengan yang dibutuhkan oleh peneliti karena peneliti membutuhkan kelas eksperimen dan kelas kontrol dengan kemampuan yang hampir sama atau homogen.

Adapun instrumen pada penelitian ini adalah soal HOTS dengan indikator yang mengacu pada tingkatan tertinggi pada taksonomi Bloom revisi Anderson \& Krathwohl (2001) yakni penggabungan dimensi pengetahuan (faktual, konseptual, prosedural, dan metakognitif) dan dimensi proses kognisi (C4-menganalisis, C5mengevaluasi, dan C6-mencipta) yang mengacu pada tema ekosistem di kelas V. Instrumen HOTS disusun dalam bentuk uraian terbuka sebanyak 10 soal, agar HOTS siswa dapat terakomodir (Abidin, 2016). Teknik analisis data menggunakan analisis data kuantitatif yaitu uji-t. Pengolahan data pretest dan posttest akan dilakukan menggunakan program SPSS versi 24.0 for Windows.

\section{HASIL DAN PEMBAHASAN}

Berdasarkan hasil pengolahan dan analisis data pada penelitian ini, didapatkan data pretest dan posttest. Melalui data tersebut kita dapat menarik kesimpulan tentang pengaruh model pembelajaran RADEC terhadap HOTS siswa. Pertama, penting untuk melihat data pretest karena kita dapat melihat apakah ada 
perbedaan HOTS siswa sebelum diberi perlakuan menggunakan model pembelajaran. Berikut disajikan statistik deskriptif HOTS siswa sebelum diberi perlakuan

Tabel 1. Statistik Deskriptif Pretest

\begin{tabular}{cccccccc}
\hline \multicolumn{3}{c}{ Kelas Eksperimen } & \multicolumn{4}{c}{ Kelas Kontrol } \\
\hline Mean & Median & Variance & Std. dev & Mean & Median & Variance & Std. dev \\
\hline 40.44 & 37.50 & 132.89 & 11.52 & 38.14 & 40 & 116.24 & 10.78
\end{tabular}

Berdasarkan tabel di atas, dapat diperoleh informasi bahwa rata-rata HOTS siswa pada kelas eksperimen sebesar 40.44 dengan data tengah 37.50 , variansi 132.89, dan standar deviasi sebesar 11.52. Sementara pada kelas kontrol diperoleh rata-rata HOTS sebesar 38.14, data tengah 40, variansi 116.24, dan standar deviasi sebesar 10.78. Bila dilihat secara seksama, data pretest menunjukkan terdapat perbedaan antara kelas eksperimen dan kelas kontrol meskipun tidak terlalu signifikan. Tidak terlalu signifikan ini dikarenakan skor setiap item di atas tidak terlalu beda jauh. Untuk lebih meyakinkan, maka selanjutnya dilakukan uji perbedaan rerata dengan taraf signifikansi sebesar 5\%. Namun sebelum diujikan perlu dipastikan terlebih dahulu apakah data normal dan homogenya. Setelah diketahui baik data pretest kelas eksperimen maupun kontrol normal dan hoomogen, maka selanjutnya dilakukan uji perbedaan dua rerata dengan bantuan program SPSS versi 24. Berikut disajikan hasil analisisnya.

\section{Tabel 2. Independent Sample t-test}

\begin{tabular}{llrrr}
\hline Skor & \multicolumn{3}{c}{ t-test for Equality of Means } \\
\cline { 3 - 5 } & & $\mathrm{t}$ & $\mathrm{df}$ & \multicolumn{1}{c}{ Sig. (2-tailed) } \\
\cline { 2 - 5 } & Equal variances assumed & .747 & 51 & .459 \\
Equal variances not assumed & .750 & 50.880 & .457 \\
\hline
\end{tabular}

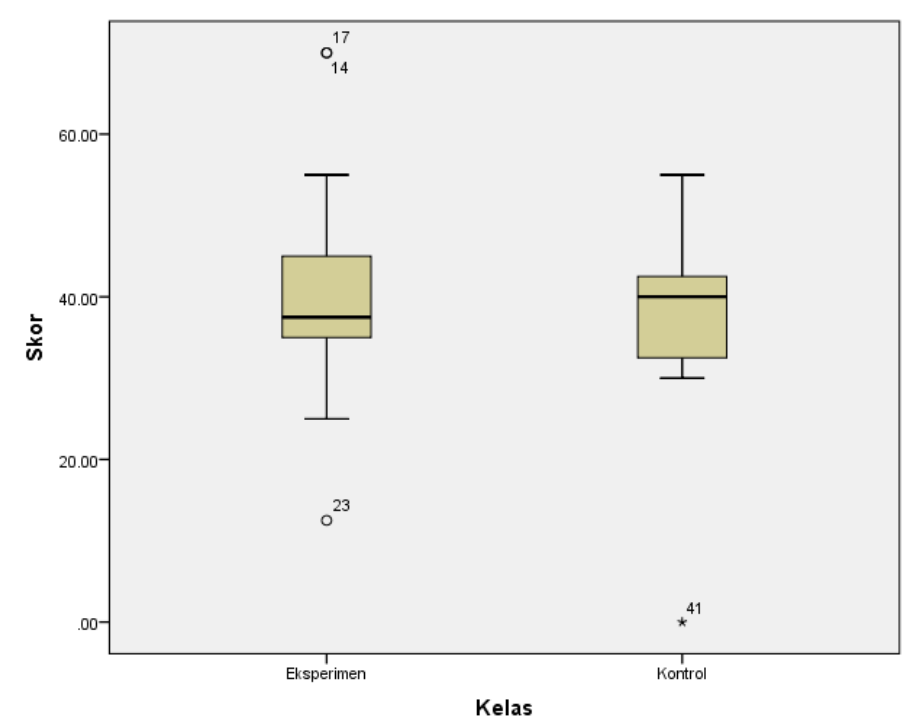

Gambar 1. Boxplot pretest HOTS siswa 
Berdasarkan tabel 2, dapat dilihat bahwa nilai t hitung pretest sebesar 0.747 dengan probabilitas sebesar 0.459. Maka dapat disimpulkan bahwa tidak terdapat perbedaan yang signifikan kemampuan HOTS awal siswa kelas eksperimen dengan kelas kontrol, karena nilai probabilitas lebih besar dari $0,05(0,459>0,05)$. Untuk melihat secara jelas mengenai pernyataan di atas, peneliti sajikan boxplot pada gambar 1.

Berdasarkan gambar di atas, jelas bahwa kemampuan awal siswa, dalam hal ini HOTS siswa baik di kelas kontrol maupun di kelas eksperimen tidak terdapat perbedaan yang signifikan. Hal ini menunjukkan hasil yang positif, karena dengan data awal yang sama, kesimpulan penelitian pun akan lebih mudah didapat. Selain itu data ini menunjukkan bahwa teknik matching dalam pengembilan sampel terbukti positif.

Langkah selanjutnya untuk memeperoleh kesimpulan yakni mengolah data posttest. Pengolahan ini akan sangat berpengaruh terhadap pengambilan kesimpulan penelitian. Berikut peneliti sajikan hasil statistik deskriptif data posttest.

Tabel 3. Statistik Deskriptif Posttest

\begin{tabular}{cccccccc}
\hline \multicolumn{3}{c}{ Kelas Eksperimen } & \multicolumn{4}{c}{ Kelas Kontrol } \\
\hline Mean & Median & Variance & Std. dev & Mean & Median & Variance & Std. dev \\
\hline 70.08 & 70 & 188.649 & 13.73 & 56.50 & 57.50 & 132.81 & 11.52 \\
\hline
\end{tabular}

Berdasarkan tabel di atas, kita ketahui bahwa rata-rata HOTS siswa pada kelas eksperimen setelah diberikan perlakuan dengan menggunakan model pembelajaran RADEC adalah sebesar 70.08 dengan data tengah 70, variansi 188.649, dan standar deviasi sebesar 13.73. Sementara itu, skor rata-rata HOTS siswa yang telah diberikan perlakuan model pembelajaran inkuiri pada kelas kontrol diperoleh sebesar 56.50, data tengah 57.50, variansi 132.81, dan standar deviasi sebesar 11.52. berkaca pada skor pretest maka dapat kita ketahui bahwa terdapat pengaruh positif baik di kelas eksperimen maupun kelas kontrol. Skorskor pada data posttest mengalami peningkatan dan ini adalah tanda terdapat pengaruh positif.

\section{Tabel 4. Independent Sample t-test Posttest}

\begin{tabular}{llrr}
\hline Skor & \multicolumn{3}{c}{ t-test for Equality of Means } \\
\cline { 2 - 5 } & \multicolumn{1}{l}{ t } & df & Sig. (2-tailed) \\
\hline Equal variances assumed & 3.876 & 51 & .000 \\
Equal variances not assumed & 3.915 & 50.820 & .000 \\
\hline
\end{tabular}

Meskipun skor rata-rata kelas eksperimen dengan kontrol berbeda cukup signifikan, namun demikian tetap harus dilakukan uji perbedaan dua rerata agar lebih menyakinkan secara statistik (ilmiah). Dengan menggunakan taraf 
signifikansi 5\% dan telah diketahui data normal dan homogen, berikut disajikan hasil pengolahan uji perbedaan dua rerata pada posttest.

Berdasarkan tabel 4, dapat kita ketahui bahwa nilai t hitung yakni sebesar 3.876 , nilai tersebut sesuai dengan nilai probabilitas yaitu 0.000 dan nilai tersebut lebih kecil jika dibandingkan dengan nilai taraf signifikansi $(0.000<0.05)$. Berdasarkan nilai tersebut dapat disimpulkan bahwa terdapat perbedaan HOTS yang signifikan antara siswa kelas eksperimen yang memperoleh pembelajaran menggunakan model pembelajaran RADEC dengan siswa kelas kontrol yang memperoleh pembelajaran menggunakan model pembelajaran inkuiri. Untuk lebih jelas melihat gambaran perbedaannya, dapat kita lihat dalam boxplot dibawah ini.

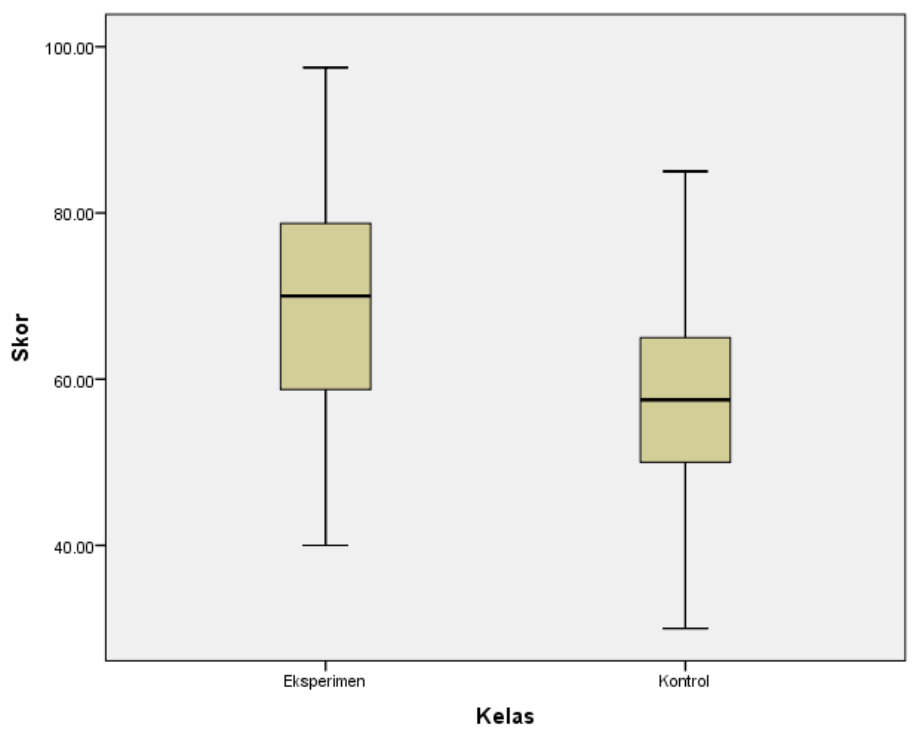

Gambar 2 Boxplot posttest HOTS siswa

Berdasarkan gambar di atas, terlihat bahwa kotak pada kelas eksperimen jauh lebih tinggi jika dibandingkan kotak pada kelas kontrol. Hal ini membuktikan bahwa terdapat perbedaan yang signifikan antara kelas eksperimen dengan kelas kontrol. Dari gambar di atas juga terlihat bahwa HOTS siswa yang memperoleh pembelajaran RADEC lebih tinggi dibandingkan dengan siswa yang memperoleh pembelajaran inkuiri. Hal tersebut merupakan hasil yang cukup luar biasa, karena kita ketahui bersama bahwa model pembelajaran inkuiri telah disepakati oleh para ahli menjadi model pembelajaran yang dapat meningkatkan HOTS siswa secara signifikan. Dengan demikian, hasil penelitian ini memberikan sebuah solusi alternatif lain untuk meningkatkan HOTS, yakni menggunakan model pemeblajaran RADEC yang notabennya adalah model pembelajaran yang sesuai dengan konteks keindonesiaan. Lebih jelas untuk melihat peningkatan, dapat dilihat pada tabel selisih rata-rata berikut.

Tabel 5 Selisih HOTS siswa

\begin{tabular}{ccc}
\hline & Rata-Rata Kelas Eksperimen & Rata-Rata Kelas Kontrol \\
\hline Pretest & 40.44 & 38.14 \\
Posttest & 70.08 & 56.50 \\
Selisih (N-Gain) & 29.64 & 18.36 \\
\hline
\end{tabular}


Peningkatan HOTS siswa baik di kelas eksperimen maupun kontrol disebabkan karena kedua model pembelajaran yang digunakan sudah memenuhi syarat pembelajaran abad 21 yang mana pusat pembelajaran adalah siswa. Baik model pembelajaran RADEC sebagai kelas eksperimen maupun model pembelajaran inkuiri sebagai kelas kontrol keduanya memiliki pengaruh positif terhadap HOTS siswa. Model pembelajaran inkuiri dapat meningkatkan HOTS siswa sebesar 18.36 dan model pembelajaran RADEC memberikan peningkatan sebesar 29.64 terhadap HOTS siswa.

Meski keduanya memiliki pengaruh positif karena sama-sama berpusat pada siswa, sebagaimana yang diungkapkan oleh Nugroho (2018) bahwa model pembelajaran yang mengaktifkan siswa akan mampu mengembangkan HOTS. Namun demikian siswa yang memperoleh pembelajaran menggunakan model pembelajaran RADEC cenderung lebih tinggi skor reratanya jika dibandingkan dengan siswa yang belajar menggunakan pembelajaran inkuiri. Hal tersebut dibuktikan dengan nilai uji t pada posttest yakni 0.000 yang artinya terdapat perbedaan yang signifikan antara HOTS siswa setelah belajar mealui model pembelajaran RADEC dan inkuiri. Sehingga hasil ini menginsyaratkan bahwa model pembelajaran RADEC lebih efektif dan berpengaruh positif terhadap HOTS dibandingkan dengan model pembelajaran inkuiri dalam tema ekosistem.

Hal yang mendasari peningkatan yang cukup signifikan dalam model pembelajaran RADEC adalah bahwa sintaks model pembelajaran RADEC sesuai dengan karakteristik siswa Indonesia. Tahap pertama yakni READ menjadikan model pembelajaran ini berbeda dengan model pembelajaran yang kebanyakan diimpor dari barat karena model pembelajaran RADEC memperhatikan betul kebutuhan siswa Indonesia, yaitu tingkat literasi, yang mana tingkat kebiasaan membaca akan berbanding lurus dengan kemampuan literasi. Semakin tinggi kemampuan literasi maka semakin tinggi pula HOTSnya (Nourdad, Masoudi, \& Rahimali, 2018). Pada tahap ini siswa diminta untuk membaca bahan ajar yang telah guru susun sesuai indikator sebelum dimulai pembelajaran atau dilaksanakan di rumah. Untuk membimbing siswa dalam proses membaca, guru memberikan pertanyaan prapembelajaran yang disusun sesuai indikator yang harus dicapai siswa dalam materi ekosistem. Kegiatan membaca ini sangat penting dan harus termuat dalam proses inti pembelajaran agar pembelajaran bisa dilaksanakan lebih efektif dan bermakna (Tuba, 2017), dan hal tersebut sudah termuat dalam model pembelajaran RADEC. Sehingga kegiatan tersebut membuktikan siswa lebih siap belajar karena dengan begitu siswa sudah punya bekal konsep dan materi sebelum melaksanakan pembelajaran maka siswa dapat melaksanakan pembelajaran lebih efektif.

Untuk melihat umpan balik siswa pada tahap READ, maka tahap selanjutnya adalah ANSWER. Pada tahap ini guru memberikan soal pascamembaca untuk melihat siswa mana yang membaca dan tidak membaca. Hal ini sejalan dengan pernyataan Musingafi \& Muranda (2014) melalui pertanyaan guru dapat memantau kompetensi para siswanya. Lebih lanjut, kegiatan ANSWER ini untuk 
menunjukkan bahwa sebelum pembelajaran dimulai siswa sudah memahami materi secara baik. Sehingga proses pembelajaran selanjutnya bisa difokuskan kepada halhal yang belum dipahami siswa, dan ini lah yang dinamakan pembelajaran efektif (Pratama, 2019).

Selanjutnya, pada tahap DISCUSS terlihat bahwa siswa aktif dan bersemangat, karena siswa sebelumnya sudah memiliki bekal materi yang sangat cukup untuk mendiskusikan masalah, dalam hal ini ekosistem. Perihal definisi, konsep, contoh rantai makanan sudah siswa pahami secara baik sehingga proses diskusi berjalan dengan baik dan bergairah. Meski suasana kelas menjadi ramai dan sempat tidak terkontrol, namun justru suasana seperti ini lah yang dapat membangun HOTS, yakni keterampilan berpikir analitis (C4). Hal ini sejalan dengan penelitian (Murphy, Meredith, Ramani, \& Silverman, 2014) yang menyimpulkan bahwa keterampilan kritis-analitis dapat dibangun melalui diskusi atau percakapan menantang. Proses diskusi dalam model pembelajaran RADEC tentu berbeda dengan model pembelajaran inkuiri di kelas kontrol, karena secara konten, siswa yang belajar menggunakan pembelajaran RADEC sudah lebih matang dan siap. Proses diskusi aktif seperti ini tentu mendorong mahasiswa untuk bertanya dan belajar menggunakan strategi pemecahan masalah, hal tersebutlah yang dapat membangun HOTS (Petrovska \& Stavreva, 2013).

Peningkatan HOTS yang cukup signifikan ini didukung pula pada tahap EXPLAIN yang mana siswa akan mengembangkan keterampilan berpikir tingkat tinggi, lebih khusus keterampilan evaluasi yang dalam taksonomi Bloom revisi masuk pada ranah C5 melalui proses pembelajaran komunikatif. Proses pembelajaran komunikatif memang terbukti baik dalam melatih siswa dalam berpikir, seperti dibuktikan oleh penelitian Jabeen (2014) dalam pembelajaran bahasa Inggris. HOTS akan terbangun pada tahap ini manakala siswa saling menilai temannya denga cara memberi tanggapan terhadap hasil diskusi dari kelompok lain. Dalam memberikan tanggapan tentu diperlukan proses berpikir tingkat tinggi, yakni menilai ataupun membandingkan. Kegiatan EXPLAIN yang menghendaki terjadinya komunikasi ini seyogyanya merupakan bagian integral dari pembelajaran inovatif seperti yang terdapat dalam sintaks model pembelajaran inkuiri yang sudah terbukti dapat mengembangkan HOTS (Duran \& Dokme, 2016; Hugerat \& Kortam, 2014; Madhuri, Kantamreddi, \& Prakas, 2012; Yuliati, Riantoni, \& Muffti, 2018) namun demikian tahap EXPLAIN pada model pemeblajaran RADEC lebih interaktif dan komunikatif. Kegiatan presentasi dalam pembelajaran inkuiri cenderung kurang bergairah. Hal tersebut dikarenakan siswa belum sepenuhnya bisa belajar dari proses penyelidikan, berbeda dengan siswa dalam model pembelajaran RADEC yang sebelumnya sudah dibekali materi ajar. Hal ini membuktikan bahwa kegiatan presentasi lebih baik pada siswa yang memperoleh pembelajaran RADEC.

Selanjutnya, tahap akhir pada model RADEC yakni CREATE jelas sekali dapat mengembangkan HOTS, karena level tertinggi dari HOTS adalah mencipta. Kegiatan dalam tahap ini adalah mengembangkan ide-ide kreatif siswa dalam 
kegiatan pembuatan produk. Pembuatan produk tersebut tidak dibatasi oleh guru, dalam artian guru membebaskan siswa untuk mewujudkan ide kreatifnya dalam sebuah karya. Hal tersebut sejalan dengan penelitian Jumanto et al., (2018) yang menyimpulkan bahwa model pembelajaran RADEC dapat meningkatkan keterampilan berpikir kreatif siswa. Dengan demikian terdapat relevansi antara model RADEC dengan HOTS, yakni pada tahap CREATE kemampuan berpikir kreatif siswa akan mampu terbangun. Hal tersebut terlihat dari ide-ide solutif yang dihasilkan oleh siswa pada kelas eksperimen yang kentara sekali dengan level kognitif C6.

\section{SIMPULAN}

Berdasarkan hasil temuan dan pembahasan yang telah dikemukakan sebelumnya, dapat disimpulkan bahwa HOTS siswa pada kelas eksperimen yang memperoleh pembelajaran menggunakan model pembelajAran RADEC mengalami peningkatan sebesar 29.64. Peningkatan tersebut dapat dilihat dari selisih nilai rata-rata pada saat pretes sebesar 40.44 dengan nilai rata-rata saat posttest sebesar 70.08. Sementara HOTS siswa pada kelas kontrol yang memperoleh pembelajaran inkuiri mengalami peningkatan sebesar 18.36. Peningkatan tersebut dapat dilihat dari selisih nilai rata-rata pada saat pretest sebesar 38.14 dengan nilai rata-rata saat posttest sebesar 56.50 .

Selanjutnya, terdapat perbedaan HOTS yang signifikan antara siswa yang memperoleh pembelajaran menggunakan model RADEC dengan model pembelajaran inkuiri karena nilai taraf signifikansinya adalah 0,000 , yang artinya nilai taraf signifikansi kurang dari $0,05(0,001<0,05)$. Maka dari itu, hasil analisis membuktikan bahwa terdapat perbedaan HOTS yang signfikan antara siswa pada kelas eksperimen yang menggunakan model RADEC dengan siswa pada kelas kontrol yang menggunakan model pembelajaran inkuiri.

Berdasarkan hasil pengolahan dan analisis data, dapat kita simpulkan bahwa model pembelajaran RADEC lebih berpengaruh positif terhadap HOTS dibandingkan dengan model pembelajaran inkuiri. Namun demikian, kita tidak bisa mengatakan model pembelajaran RADEC lebih baik dari model pembelajaran Inkuiri karena keterbatasan penelitian ini.

Model pembelajaran RADEC masih perlu diujikan kembali karena model ini masih tergolong baru. Model pembelajaran RADEC perlu diuji untuk karakteristik siswa yang berbeda atau jenjang yang berbeda agar hasil generalisir dapat lebih luas.

Selanjutnya, secara tersirat dapat diketahui bahwa tahapan model pembelajaran RADEC telah berhasil meningkatkan HOTS, namun harus diadakan penelitian lanjutan yang khusus menganalisis keterkaitan antara sintaks dengan HOTS seperti tahap DISCUSS dengan menganalisis (C4), tahap EXPLAIN dengan mengevaluasi (C5), dan CREATE dengan mencipta (C6) 


\section{DAFTAR PUSTAKA}

Abdullah AH. (2017). Mathematics Teachers' Level of Knowlegde and Practice on the Impementation of Higher-Order Thinking Skills (HOTS). Journal of Mathematics Science and Technology Education, 13(1), 3-17.

Abidin, Y. (2016). Revitalisasi Penilaian Pembelajaran. Bandung: Refika Aditama.

Acar, O., \& Aybars, T. (2018). Using the inquiry-based learning approach to enhance student innovativeness: a conceptual model. Teaching in Higher Education. https://doi.org/10.1080/13562517.2018.1516636

Anderson, L., \& Krathwohl, D. (2001). A Taxonomy of Learning, Teaching, and Assessing. New York: A Revision of Bloom's Taxonomy of Educational Objectives.

Binkley, M. (2012). Defining Twenty-First Century Skills" dalam Assessment and Teaching of 21 st Century Skills. New York: Springer.

Brookhart, S. (2010). How to Assess High-er Order Thinking Skills in Your Classroom. Alexandria: ASCD.

Duran, M., \& Dokme, I. (2016). The effect of the inquiry-based learning approach on student's critical-thinking skills. Eurasia Journal of Mathematics, Science \& Technology Education, 12(12), 2887-2908. https://doi.org/10.12973/eurasia.2016.02311a

Fatchiyah. (2016). Pengaruh PBL Terhadap Kemampuan Berpikir Tingkat Tinggi Siswa Kelas V Sd Se-Gugus 01 Kretek. Jurnal Pendidikan Guru Sekolah Dasar, 5(18), 737-745.

Fitri, H., Dasna, I., \& Suarjo. (2018). Pengaruh Model Project Based Learning (PjBL) Terhadap Kemampuan Berpikir Tingkat Tinggi Ditinjau dari Motivasi Berprestasi Siswa Kelas IV Sekolah Dasar. BRILIANT: Jurnal Riset Dan Konseptual, 3(2), 201-212. https://doi.org/http://dx.doi.org/10.28926/briliant.v3i2.187

Hugerat, M., \& Kortam, N. (2014). Improving Higher Order Thinking Skills among freshmen by Teaching Science through Inquiry. Eurasia Journal of Mathematics, Science \& Technology Education, 10(5), 447-454.

Jabeen, S. (2014). Implementation of Communicative Approach. English Language Teaching, 7(8), 68-74.

Jumanto, A., Kuncoro, Y., Handayani, \& Suryana. (2018). The Effect Of Radec Model And Expositorial Model On Creative Thinking Ability In Elementary School Students In Suralaya. In Syaodih, Sujana, \& William (Eds.), Prosiding International Conference on Elementary Education (pp. 561-567). Universitas Pendidikan Indonesia.

Lukmanudin. (2018). Penguasaan Konsep IPA dan Kemampuan Menjelaskan Perpindahan Zat Pencemar Mahasiswa PGSD melaui Pembelajaran Read-Answer-Discuss-Explain-and Create. Universitas Pendidikan Indonesia.

Madhuri, V., Kantamreddi, \& Prakas, G. (2012). Promoting higher order thinking skills using inquiry-based learning. European Journal of Engineering Education, 37(2), 117-123.

Murphy, P., Meredith, R., Ramani, G., \& Silverman, R. (2014). Promoting CriticalAnalytic Thinking in Children and Adolescents at Home and in School. Educ Psychol Rev, 26, 561-578. https://doi.org/10.1007/s10648-0149281-3 
Musingafi, C., \& Muranda, E. (2014). Students and Questioning: A Review of the Role Played By Students Generated Questions in the Teaching and Learning Process. Studies in Social Sciences and Humanities, 1(3), 101107.

Nourdad, N., Masoudi, S., \& Rahimali, P. (2018). The Effect of Higher Order Thinking Skill Instruction on EFL Reading Ability. Journal of Applied Linguistics \& English Literature, 7(3), 231-237. https://doi.org/http://dx.doi.org/10.7575/aiac.ijalel.v.7n.3p.231

Nugroho, R. (2018). HOTS (Kemampuan Berpikir Tingkat Tinggi: Konsep, Pembelajaran, Penilaian, dan Soal-soal). Jakarta: PT Gramedia Widiasarana Indonesia.

Nurhayatii, \& Anggraeni, L. (2017). Analisis Kemampuan Berpikir Tingkat Tinggi Mahasiswa (Higher Order Thinking) dalam Menyelesaikan Soal Konsep Optika melalui Model Problem Based Learning. Jurnal Penelitian \& Pengembangan Pendidikan Fisika, 3(2), 119-126. https://doi.org/doi.org/10.21009/1.03201

OECD. (2013). PISA 2012 Results: What Students Know and Can Do Student Performance in Mathematics, Reading and Science Volume I.

OECD. (2017). Educational Opportunity for All. https://doi.org/10.1787/9789264287457-en

Petrovska, S., \& Stavreva, S. (2013). Contemporary Pedagogical Approaches for Developing Higher Level Thinking on Science Classes. Procedia - Social and Behavioral Sciences. In Procedia - Social and Behavioral Sciences (pp. 702-710). Retrieved from http://doi.org/10.1016/j.sbspro.2013.08.742

Pratama, Y. (2019). Pengaruh Model Pembelajaran RADEC dan Inkuiri Terhadap Keterampilan Berpikir Tingkat Tinggi Mahasiswa PGSD Pada Perkuliahan IPA. Universitas Pendidikan Indonesia.

Saido, G., Siraaj, S., Nordin, A., \& Amedy, A. (2015). Higher Order Thinking Skills Among Secondary School Students in Science Learning. The Malaysian Online Journal of Educational Science, 3(3), 13-20.

Sopandi, W. (2017). The Quality Improvement of Learning Processes and Achievements Through the Read-Answer-Discuss-Explain-and. In M. Keong, L. Hong, \& R. Rao (Eds.), Proceeding 8th Pedagogy International Seminar 2017 (pp. 132-139). Kuala Lumpur: Institut Pendidikan Guru Kampus Ilmu Khas.

Sopandi, W., Pratama, Y., \& Handayani, H. (2018). Profil Perubahan Kompetensi Pedagogik Guru Pendidikan Dasar Dan Menengah Melalui Sosialisasi Dan Workshop Read-Answer-Discuss-Explain-And Create (RADEC). Premiere Educandum: Jurnal Pendidikan Dasar Dan Pembelajaran, 8(1).

Tembang, Y., \& Suharjo. (2017). Peningkatan Motivasi Dan Hasil Belajar Melalui Model Pembelajaran Think Pair Share Berbantuan Media Gambar Di Sekolah Dasar. Jurnal Pendidikan Universitas Negeri Malang, 2(6), 812817.

Trilling, B., Fadel, C. (2009). 21st Century Skills: Learning for Life in Our. San Francisco: Jossey-Bass A Wiley Imprint.

Tuba, S. (2017). A study on reading habits of social studies and history teachers in Turkey. Educational Research and Reviews, 12(10), 569-52. https://doi.org/10.5897/ERR2017.3245 
Yee, M., Othman, W., Yunos, J., Tee, T., \& Mohammad, M. (2011). The Level of Marzano Higher Order Thinking Skills among Technical Education Students. International Journal of Social Science and Humanity, 1(2), $121-125$.

Yuliati, L., Riantoni, C., \& Muffti, N. (2018). Problem Solving Skills on Direct Current Electricity through Inquiry-Based Learning with $\mathrm{PhET}$ Simulations. International Journal of Instruction, 11(4), 123-138. 